\title{
Maternal Deaths in Giza in the New Millennium: A Hospital
}

\section{Based Retrospective Study}

\author{
Arwa M. El-Shafei* ${ }^{*}$ Mostafa A. Mostafa, ${ }^{* *}$ Ahmed A. Abdallah ${ }^{\star *}$, Faida Amin Abdel Latif***
}

\begin{abstract}
Background: Health institutions need to contribute their quota towards the achievement of the Millennium Development Goal (MDG) with respect to maternal health. In order to do so, current data on maternal mortality are essential for health care providers and policy makers to study the burden of the problem and understand how best to distribute resources. This study presents the magnitude and distribution of the causes of the maternal deaths at the beginning of the $21^{\text {st }}$ century in an Egyptian general hospital and derives recommendations to reduce their frequency. Objectives: to identify and assess the factors contributing to maternal mortality, especially the hospital-relevant ones, and to determine the most preventable causes in order to reduce the maternal mortality ratio (MMR) calculated for Embaba General Hospital. Methods: This is a retrospective study of mortality records of obstetric cases at Embaba General Hospital during the period between (January $1^{\text {st }}$ 2001) and (December $31^{\text {st }}$ 2010). Results: There were 41 maternal deaths and 52096 live births during the study period. Thirty six mothers $(87.8 \%)$ died due to direct causes while only five deaths $(12.2 \%)$ were due to indirect maternal causes. The major causes of deaths were obstetric haemorrhage $(56.1 \%)$, pulmonary embolization (17.0\%) and eclampsia (12.2\%). The maternal mortality ratio was 78.7 per 100,000 live births. Conclusion: In the first decade of the new millennium, a large number of pregnant women receiving care continued to die from preventable causes of maternal deaths. Adoption of evidence-based protocol for the management of hemorrhage and improvement in the quality of obstetric care of emergencies would go a long way to significantly reduce the frequency of maternal deaths at this hospital.
\end{abstract}

Key Words: Maternal Mortality, MDG

\section{INTRODUCTION}

The last decade of the $20^{\text {th }}$ century developing countries. Failure of the Safe witnessed intensive mobilization of Motherhood Initiative, proposed by the World international health and development Health Organization (WHO) in 1987, and other agencies to reduce maternal deaths in the similar programs in globally addressing the

\footnotetext{
${ }^{*}$ Departments of Public Health and Community Medicine, and

${ }^{* *}$ Obstetrics and Gynecology, Faculty of Medicine, Cairo University, Egypt,

${ }^{* * *}$ Embaba General Hospital Giza, Egypt
} 
issue of maternal mortality by the year 2000 led to setting of new goals for the present millennium. One of the key Millennium Development Goals (MDG), which the United Nations Member States pledged to meet by 2015, is improvement in maternal health by reducing the maternal mortality ratio (MMR) to three quarters of the 1990 data. ${ }^{(1)}$ Among the principal obstacles to appropriate distribution of resources targeted towards improving maternal healthcare is the lack of accurate data on the number, causes and local factors influencing adverse maternal outcomes.

Maternal mortality in Egypt was accurately calculated for the first time by a survey done in 1992. A second survey was done in 2000 , and since then a surveillance system was established in order to determine maternal mortality annually. The 2000 maternal mortality survey showed that about three-fourths of maternal deaths in the country were due to direct obstetric causes. Haemorrhage, or severe bleeding, was the most significant direct cause, followed by hypertensive disorders of pregnancy e.g. "pregnancy-induced hypertension (PIH), pre-eclampsia, and eclampsia", ruptured uterus, infection, and pulmonary embolism. Among the indirect causes, are conditions aggravated by pregnancy such as cardiovascular diseases (e.g. rheumatic heart disease ; RHD) and anemia were the most significant. The results of the surveillance study in 2007 were 1141 deaths from a total of 2,065,496 live births with maternal mortality ratio of 55 per 100,000 live births and maternal mortality rate of $5 \cdot 2 .^{(2,3)}$.

Egypt was considered as one of the leading countries in reducing maternal mortality. This was not only done by reducing maternal deaths, but also by using an effective and a successful surveillance system. In the period between 1992 and 2000, Egypt decreased the maternal mortality ratio from 174 to 84 per 100,000 live births and this was nearly $52 \% .^{(4,5)}$ In spite of their shortcomings, 
hospital-based studies are relatively easy to perform and can also provide substantial and useful information, even if the results are likely to be influenced by referral bias. Local enquiries into maternal deaths over a given period can be used to monitor as well as to indicate measures for improving the quality of obstetric care provided in a health facility. ${ }^{(6)}$

In order for health institutions to contribute their quota towards the achievement of the MDG with respect to maternal health, current data on maternal mortality are essential for the care providers and policy makers to assess the burden of the problem and understand how best to distribute resources. ${ }^{(7)}$

This study presented the magnitude and distribution of causes of maternal mortality at the beginning of the $21^{\text {st }}$ century in an Egyptian Governmental hospital and derives recommendations to reduce the frequency of maternal deaths in this hospital and in other hospitals in similar settings.

Study objectives: The current study aimed to review maternal mortality records in the previous 10 years at Embaba General Hospital, Giza, Egypt in order to identify and assess the factors contributing to maternal mortality, especially the hospital relevant ones, and to determine the most preventable causative factors to decrease the maternal mortality ratio calculated for Embaba General Hospital.

\section{METHODOLOGY:}

\section{Study design and settings:}

This study is a retrospective analytic study of the mortality records of obstetric cases at Embaba General Hospital during the period from "January $1^{\text {st }} 2001$ " to "December $31^{\text {st }} 2010 "$. The following definitions were functioned in the study:

Maternal Mortality was defined according to the $10^{\text {th }}$ revision of the International Classification of Diseases (ICD-10) by WHO. ${ }^{(8)}$ as the death of a woman while pregnant or within 42 days of termination of pregnancy, irrespective of the duration and the site of the pregnancy, from any cause related to or aggravated by the pregnancy or its 
management, but not from accidental or incidental causes. Direct causes for maternal deaths are those resulting from complications of the pregnant state (pregnancy, labour and puerperium), from interventions, omissions, incorrect treatment, or from a chain of events arising from any of the above while indirect maternal deaths are those attributed to a previously existing disease or disease that develop during pregnancy, and not due to direct obstetric causes but which was aggravated by the physiological effects of pregnancy. Maternal mortality ratio was defined as the number of maternal deaths per 100,000 live births.

\section{Data collection tools:}

Data were collected by reviewing the cases' files and database records of the Department of Obstetrics and Gynecology at Embaba General Hospital, and reviewing the database records of maternal deaths in the Ministry of Health and Population as some patients' data were incomplete especially those belonging to the first half of the study.

Data were collected using a spread sheet for the $\mathbf{n}$ number of maternal deaths, antenatal care and diagnosis of diseases during antenatal period, birth attendant, and final cause of death, management done including; admission at intensive care unit, blood transfusion, surgical intervention and consultants' availability.

Inclusion criteria: All maternal deaths during pregnancy or within 42 days after termination of pregnancy including a direct maternal death that is the result of a complication of the pregnancy, delivery, or their management, and an indirect maternal death that is a pregnancy-related death in a patient with a pre-existing or newly developed health problem.

Exclusion criteria: All deaths during but unrelated to a pregnancy which are termed accidental, incidental, or non obstetrical maternal deaths, or maternal deaths after 42 days from termination of 
pregnancy.

Ethical considerations and administrative regulations:

All data were collected under complete confidentiality and following administrative regulations by reviewing the files and the database after agreement of both the general manger and the chairman of the Medical Records Department at the hospital.

Data analysis: Data were entered into a computer database using Microsoft Excel software and analyzed with SPSS version 15 and Epi info 2002 statistical package. ${ }^{(9)}$ Results were presented in frequencies, percentages and summary statistics. MMR was determined for different age and parity groups and for each year of study. The confidence limits of the MMR for each year of study were also calculated at $95 \%$ confidence level. The relationship between maternal deaths and operative deliveries (caesarean section, instrumental delivery, destructive operations) was explored.
Comparison of categorical variables was done by computing the odds ratio (OR) at 95\% confidence limits. Observed differences between two samples were considered statistically significant where $p<$ 0.05

\section{RESULTS}

During the period of study, there were 52096 live births and 41 maternal deaths. the present data were retrieved from the statistical department of Embaba Hospital, if the needed data were unavailable they were completed by reviewing the database records of maternal deaths in the Ministry of Health and Population as some patients' data were incomplete especially those belonging to the first half of the study Table 1 displays the distribution of maternal deaths throughout the ten years. The highest percentage was that for 2006 (21.2\%). The calculated maternal mortality ratios for each individual year was presented in figure 1 which illustrates the highest ratios for years 2003 and 2004 (174 
and $173 / 100.000$ live births) respectively lowest value in 2010 (45.9/100.000 live as well as the gradual decline in the ratios. births). Almost $73 \%$ of them had their that started from 2007 and reached the antenatal care during their pregnancy.

Table 1: 2001 - 2010 maternal deaths at Embaba General Hospital.

\begin{tabular}{ccc}
\hline \hline Year & Number & Percent \\
2001 & 3 & 7.3 \\
2002 & 3 & 7.3 \\
2003 & 7 & 17.7 \\
2004 & 7 & 17.7 \\
2005 & 2 & 4.8 \\
2006 & 5 & 21.2 \\
2007 & 4 & 9.7 \\
2008 & 4 & 9.7 \\
2009 & 3 & 7.3 \\
2010 & 3 & 7.3 \\
Total & 41 & 100.0 \\
\hline \hline
\end{tabular}

Figure 1: 2001 - 2010 maternal mortality rates at Embaba General Hospital

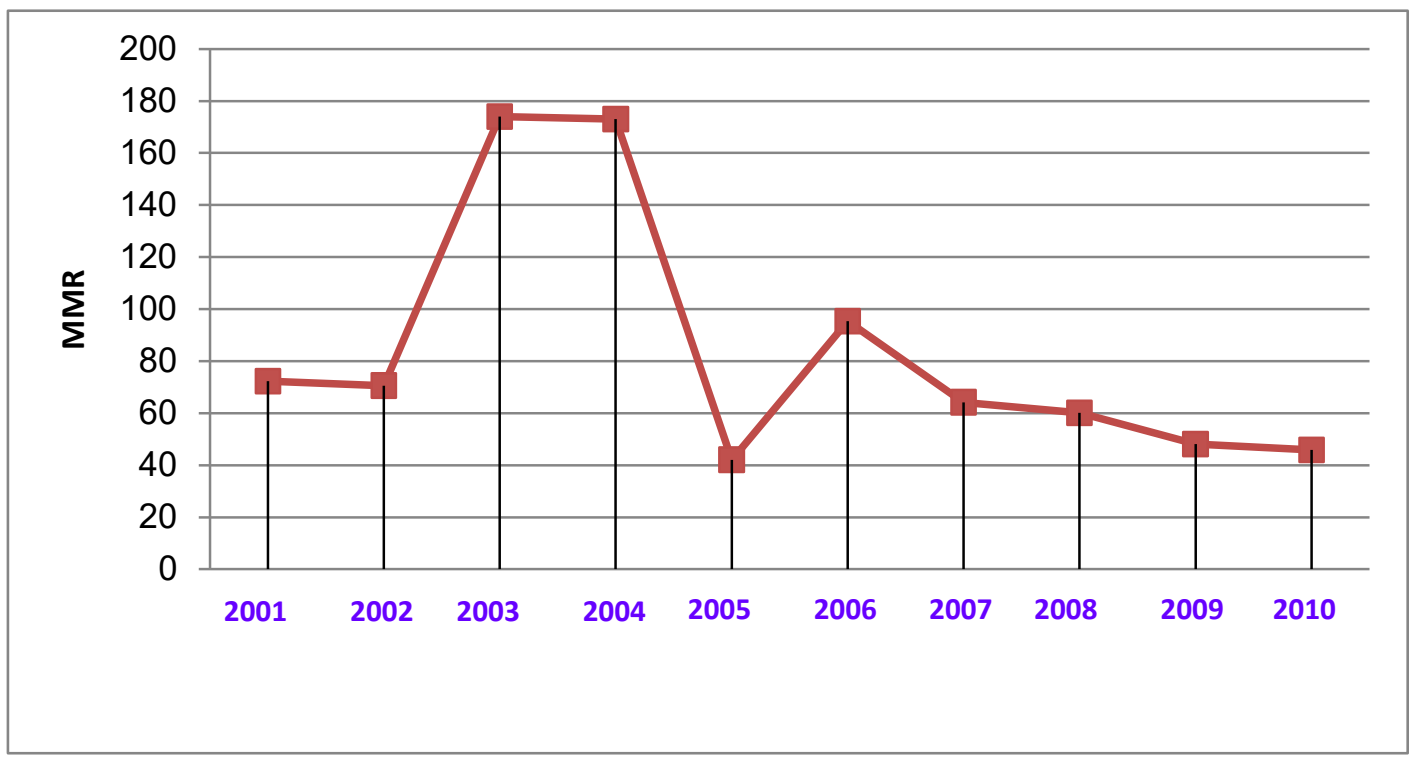


Table 2 shows the frequency of maternal deaths according to the age group of the women who died. The age ranged from 18 to 45 years with a mean of $30.37 \pm 5.89$ years. Almost 34 percent of the maternal deaths occurred in women whose age ranged from 25 to less than 30 years while about 30 percent of them were 35 years and older. MMR was lowest among those aged 20-24 years and highest among those aged less than 20 years. The noted differences were found to be statistically insignificant ( $p$-value=0.5).

Table 3 displays the maternal mortalities in relation to their previous pregnancy status. More than half $(58.5 \%)$ of the maternal deaths were belonging to women whose previous pregnancies ranged from 1 to 4 . That group of women with previous gravidity of 1-4 was considered a reference group and was functioned as a comparable group with both the zero gravidity (primigravida) and $>5$ pregnancies (grand multigravida) groups. The MMR was lowest(47.2) , modest (72.6) and highest (109) in the grand mutigravida, primigravida and gravida 1-4 groups respectively. The comparison in-between was statistically significant only between grand multigravida and gravida 1-4 groups (OR: 2.31, Cl: 1.07-4.97, $p=0.08)$.

Out of the 41 maternal deaths, 22 women showed pregnancy risks while 19 didn't. of those two groups , 23 women (7 with and 16 without pregnancy risks) received antenatal care (table 4). The differences in-between were statistically sisgnificant $(p$-value $=0.002)$

Table 2: Maternal deaths according to age distribution.

\begin{tabular}{|c|c|c|c|c|c|c|c|}
\hline \multirow[t]{2}{*}{ Age group } & \multicolumn{2}{|c|}{ Maternal death } & \multicolumn{2}{|c|}{ Total live birth } & \multirow[t]{2}{*}{ MMR/100000 } & \multirow{2}{*}{$\begin{array}{c}\text { Chi- } \\
\text { square }\end{array}$} & \multirow[t]{2}{*}{ p-value } \\
\hline & Frequ & ercent & Frequency & Percent & & & \\
\hline$<20$ & 1 & 2.4 & 920 & 1.8 & 108.6 & & \\
\hline $20-$ & 4 & 9.8 & 10938 & 20.9 & 36.6 & & \\
\hline $25-$ & 14 & 34.1 & 14653 & 28.1 & 95.5 & & \\
\hline $30-$ & 10 & 24.4 & 11826 & 22.7 & 84.5 & & \\
\hline$\geq 35$ & 12 & 29.3 & 13759 & 26.5 & 87.2 & 3.28 & 0.51 \\
\hline
\end{tabular}


Table 3: Maternal deaths according to previous pregnancy status.

\begin{tabular}{lcccccccc}
\hline $\begin{array}{l}\text { Previous } \\
\text { pregnanci } \\
\text { es }\end{array}$ & $\begin{array}{c}\text { Maternal deaths } \\
\text { Frequency Percent }\end{array}$ & $\begin{array}{c}\text { Total live birth } \\
\text { Frequency Percent }\end{array}$ & MMR/100.000 & OR & Cl & p-value \\
\hline 0 & 8 & 19.5 & 11015 & 21.1 & 72.6 & 0.6 & $0.3-1.5$ & 0.3 \\
$1: 4$ & 24 & 58.5 & 22018 & 42.3 & 109 & Reference & - & - \\
$\geq 5$ & 9 & 22.0 & 19063 & 36.6 & 47.2 & 2.3 & $1.07-5.0$ & 0.03 \\
\hline \hline
\end{tabular}

Table 4 displays the pregnancy risk and antenatal care status of the studied maternal mortalities. Out of the 41 maternal deaths, 22 women showed pregnancy risks while 19 didn't. Of those two groups, 23 women ( 7 with and 16 without pregnancy risks) received antenatal care. The differences in-between were statistically significant $(p$-value $=0.002)$ Reviewing the hospital records revealed that $73 \%$ of the antenatal care were conducted at private clinics.

Table 4: Pregnancy risk and antenatal care of the maternal deaths.

\begin{tabular}{|c|c|c|c|}
\hline Antenatal care & $\begin{array}{l}\text { Presence of pregnancy risks } \\
\text { Frequency Percent }\end{array}$ & $\begin{array}{l}\text { Absence of pregnancy risks } \\
\text { Frequency Percent }\end{array}$ & p-value \\
\hline Yes & 31.8 & 84.2 & 0.002 \\
\hline No & 68.2 & 15.8 & \\
\hline Total & 100.0 & 19100.0 & \\
\hline
\end{tabular}

Table 5 shows the various causes of $(12 \%)$, sepsis $(9.8 \%)$, and heart failure in maternal deaths during the studied rheumatic patients (4.9\%). Most (18/23) of duration. In descending order of frequency, the deaths due to hemorrhage were cases maternal deaths were caused by of postpartum hemorrhage while abortionhemorrhage $(56.1 \%)$, followed by related hemorrhage accounted for only 2 pulmonary embolism (17.0\%), eclampsia cases . 
Table 5: Maternal deaths distribution according to leading causes .

\begin{tabular}{ccc}
\hline \hline Cause & Frequency & percent \\
\hline Haemorrhge & 23 & 56.1 \\
Pulmonary embolism & 7 & 17.0 \\
Eclampsia & 5 & 12.2 \\
Sepsis & 4 & 9.8 \\
Heart failure & 2 & 4.9 \\
Total & 41 & 100 \\
\hline \hline
\end{tabular}

Thirty six $(87.8 \%)$ deliveries were consultant unavailability $(n=1,2.4 \%)$. Also lack conducted by a skilled birth attendant (doctor of needed blood transfusion was a contributing or nurses) while only five deliveries (12.2\%) cause for one death. Out of those who were in were attended by traditional Dayah (table 6). need of surgical intervention $(n=22)$ only 8

Table 7 displays contributory factors to women (36.4\%) had surgical deliveries. The maternal death as delay in referral from other difference in-between both groups was healthcare facilities $(n=6,14.6 \%)$ and delay in statistically insignficant $P=0.7, \quad$ OR1.29, receiving care at Embaba hospital due to (95)Cl;0.54-3.07).

Table 6: Distribution of maternal deaths by birth attendants

\begin{tabular}{lcc}
\hline \hline Variable & Number & Percent \\
\hline Doctor & 31 & 75.6 \\
Nurse & 5 & 12.2 \\
Dayha & 5 & 12.2 \\
Total & $\mathbf{4 1}$ & 100 \\
\hline \hline
\end{tabular}


Table 7: Hospital related factors for maternal deaths.

\begin{tabular}{lcccccc}
\hline \hline \multirow{2}{*}{ Variable } & \multicolumn{2}{c}{ Present } & \multicolumn{2}{c}{ Absent } & \multicolumn{2}{c}{ Chi- } \\
square & p-value \\
\cline { 2 - 5 } & Frequancy & percent & Frequancy & percent & \\
\hline Consultant availability & 40 & 97.6 & 1 & 2.4 & 37.1 & $<0.001$ \\
Blood avilabilty & 40 & 97.6 & 1 & 2.4 & 37.1 & $<0.001$ \\
Timelined referral & 35 & 85.4 & 6 & 14.6 & 21.5 & $<0.001$ \\
\hline \hline
\end{tabular}

\section{DISCUSSION}

This study provides a baseline data on alarmingly high MMR of 1400 deaths per maternal mortality at the beginning of this 100,000 live births in Afghanistan. ${ }^{(8-10)}$ This millennium for a general hospital in Egypt is a retrospective study of the cases of as part of the local efforts to make MDG for maternal deaths that occurred among maternal health a reality by 2015. In 2010, 52096 women admitted to the Obstetrics estimates developed by the WHO, UNICEF, and Gynecology Department of Embaba UNFPA and the World Bank suggested that General Hospital during the period from $1^{\text {st }}$ worldwide, about 260 women die per of January 2001 to the $31^{\text {th }}$ of December 100,000 live births and most of these 2010. Ten years duration ensured deaths occur in sub-Saharan Africa. ${ }^{(10)}$ considerable sample size allowing studying These estimates indicate that Africa the trend. In this study, the maternal recorded the highest maternal mortality mortality ratio (MMR), (i.e. the number of ratio (MMR) of 260 per 100,000 live births; maternal deaths per 100,000 live births) while Europe recorded the lowest MMR of was 78.7 per 100,000 live births in the ten 21 maternal deaths per 100,000 live births years, with the highest in year 2003 (174 (4). Globally, Greece recorded the lowest per 100,000 live births), the lowest (MMR) maternal deaths by country with 2 per was in year 2005 (42.1 per 100,000 live 100,000 live births compared with the births). Based on field surveys, the Ministry 
of Health and Population (MOHP) calculate MMR in 1992, was 174 per 100,000 live births and declined to 84 per 100.00 live births in 2000 , to reach about 55 per 100.00 live births in 2008..$^{(11)}$ The explanation for the difference between our study results and that of Abdel Aziz et al may be due to the small sample size in the present study compared to the national study conducted by the MOHP in year 2010 (11). The mean age of females was $30.37 \pm 5.89$. This was agreeing with enhancing equality for girls' education, and accordingly improving the overall quality of education by adopting Girls Improved Learning Outcomes (GILO) initiative, in collaboration with USAID and ascertaining changes in fertility patterns among adolescents using information from retrospective birth histories in the twenty years period preceding 2008. Egyptian Demographic Health survey confirmed the marked reduction in the fertility level for the 15-19 age group (2). Overall adolescent fertility rate decreased from 80 births per
1000 woman to 50 births in the $15-19$ age group before 2008 EDHS (Egyptian Demographic Health Survey) ${ }^{(2)}$ Also Millennium Development Goal five (MDG5) calls for a reduction in the maternal mortality ratio by three quarters by 2015 and establishment of universal access to high quality reproductive health care. Achievement of MDG5 in part requires improved provision of family planning services to enable women to have fewer, better spaced pregnancies. ${ }^{(11)}$ The highest proportion of mortalities was for women belonging to the age group 24-30 (34.1\%). This is in agreement with the results of an Indian study having $27 \%$ of their total sample in the same age group. ${ }^{(12)}$ Regarding the relation between maternal mortality and previous pregnancy status, the highest percentage of mortalities and MMR were found among women whose previous pregnancies ranged from one to four. These results are not in agreement with that reported by John and John ${ }^{(11)}$ who 
noted that the highest mortalities were for women with 5 or more parity status. ${ }^{(13)}$

In the present study, it was noted that out of 41 cases 23 (56.1\%) had received antenatal care throughout the ten years. Among those 23 deaths, seven women had been reported to have pregnancy risk which was not properly managed during pregnancy and / or delivery. This raises the suspicion on the quality of the antenatal care particularly at the private sector where $73 \%$ of the studied maternal deaths had got their antenatal care. These figures are nearly the same as those reported by 2008 EDHS which showed that women who had made antenatal visits to a trained medical provider approached $74 \% .{ }^{(10)}$ This may be explained by the fact that antenatal care in private sector gives the woman false confidence that she does not need a second opinion that may find out serious risk factors not detected by her care provider. Lacking of qualified and well trained care providers might contribute to low antenatal care quality at the private sector as well. In 2012, Fawole et al found that antenatal care services could be functioned as a predictor for maternal mortality $^{(14)}$.

The $2008 \mathrm{EDHS}^{(2)}$ indicated that physicians were the health personnel assisting $74 \%$ of deliveries and trained nurse or midwives $5 \%$, while most of the remaining births were assisted by dayas. Significant increase in the proportion of assisted deliveries was reported between 1988 and 2008, which was supposed to achieve safe motherhood ${ }^{(15)}$. This was similar to the present study where $75.6 \%$ of deliveries were conducted by doctors, $12.2 \%$ nurses, and $12.2 \%$ by dayas. This may point out poor training of the health personnel and delayed transfer to wellequipped delivery units.

Effective, rapid transfer of critical obstetric cases is a major contributing factor in saving mothers' life. Referrals to specialist services in pregnancy should be 
prioritized as urgent ${ }^{(6)}$, Although in this study non appropriate time lined referral was reported in six cases (14.60\%), yet it may reflect the delayed decision of transfer.. Deficiencies in the health care referral system have been found in previous studies as well. Ujah et al reported that mothers who had no antenatal care tended to arrive in moribund condition reflecting a weak referral system and inadequate facilities for emergency obstetric care ${ }^{(16)}$.

The present study studied blood unavailability, \& consultant unavailability, as components of hospital performance, and proved that each factor separately was responsible in only one case $(2.4 \%)$, which means that $4.8 \%$ of cases died due to defects in hospital care quality. The trend noted in other studies whereby the need for intensive care was strongly associated with maternal mortality similarly reflects poor health infrastructure. Health facilities must have qualified anesthesiologists to provide quality intensive care ${ }^{(17)}$.
The leading causes of maternal deaths in this study are not significantly different from those identified in the developing countries for several decades. ${ }^{(18)}$ This implies that our pregnant women are still dying from preventable causes of maternal deaths, ${ }^{(14)}$.In the present study. Obstetric hemorrhages were the commonest cause of maternal mortality (56.1\%). This agrees with the national study conducted by the MOHP in 2010 which referred to obstetric hemorrhages as the leading cause of Egyptian maternal mortalities ${ }^{(10)}$.

Pulmonary embolism was the second common cause of maternal mortality, 7 cases (17.0\%). This was explained by Abdel-Aziz et al who mentioned the fact that medically assisted maternal mortalities increased by the increased risks for embolization. ${ }^{(10)}$

In the present study hypertensive disorders with pregnancy accounted for $12.2 \%$. Compared to the national figures in the preceding years $13 \%{ }^{(2)}$. This is in agreement with the recommendations put by Tsu 2005 
who stated that qualified antenatal care

causes of maternal mortality.

management could reduce maternal

mortalities, ${ }^{(19}$

Conclusion: In the first decade of the new

millennium, a large number of pregnant

women receiving care continued to die from

preventable causes of maternal death.

Adoption of evidence-based protocol for the

management of hemorrhage and improvement

in the quality of obstetric care for emergencies

would go a long way to significantly reduce the

frequency of maternal deaths at Embaba

General Hospital.

\section{RECOMMENDATIONS}

Training is needed for the doctors and nurses to manage properly any emergencies. This can be achieved by training on first aid and life saving skills.

Hospital Medical records: Improve registrations system is needed to include all the relevant statistical information, the inefficiency of the current registration system proved to be difficult in obtaining complete and accurate information on the incidence and

\section{REFERENCES}

1. Haines A, Cassels A: Can Millennium Development Goals be attained? BMJ. 2004, 329:394-7.

2. Fatma E, Ann W. Egypt interim Demographic and Health Survey Cairo Egypt: Ministry of Health and Population National Population Council, 2008. [citied 2010 February20]. Available from: www.wfp.org.

3. Department of Public Health: Pregnancyassociated maternal mortality review Available from: http://www.cdph.ca.gov/data/statistics/Pag es/ CaliforniaPregnancy-Associated Mortality Review. . Last accessed September 17, 2010.

4. WHO UNICEF UNFPA and the World Bank: Trends in Maternal Mortality 1990 2008, September 2010. Available from: http://www.unfpa.org/public/site/global/lang /en/pid/ 6598. Last accessed September 17, 2010.

5. Campbell OMR, Gipson R, Issa AH. National maternal mortality ratio in Egypt halved between 1992-93 and 2000. Bull World Health Organ. 2005; 83: 462-72.

6. Kampikaho A, Irwig LM: Incidence and causes of maternal mortality in five Kampala hospitals, 1980-1986. East Afr Med J. 1991, 68:624-31.

7. Geelhoed DW, Visser LE, Asare K, Schagen van Leeuwen $\mathrm{JH}$, Van Roosmalen J. Trends in maternal mortality: a 13-year hospitalbased study in rural Ghana. Eur J Obstet Gynecol Reprod Biol. 2003, 107:135-9.

8. World Health Organization. ICD-10: International statistical classification of diseases and health-related problems. Tenth Revision Volume 2. Geneva: World Health Organization; 1993.

9. Centers for Disease Control and Prevention (CDC), World Health Organization: Epi Info 2002. In Database and statistics software for public health 
professionals Atlanta, Georgia, USA: Centers for Disease Control and Prevention. 2002.

10. WHO: Maternal mortality in 2005: estimates developed by WHO, UNICEF. Available from: http://ww.who.int/whosis/mme_2005.pdf.L ast accessed September 17, 2010.

11. Abdel-Aziz H, Elaraby A, Hamed R, Egypt's progress towards achieving the Millennium Development Goals.. BMC Public Health. 2010; 11:15.

12. Ganatra BR, Coyaji KJ Rao VN. Casecontrol study of maternal mortality in rural Maharashtra, India. Bulletin of the World Health Organization. 1998, 76 (6): 591-8.

13. John S,John R. How contraceptive use affects maternal mortality. USAID report. Available from http://www.healthpolicyinitiative.com/Public ations/Documents/668_1_TMIH_FINAL_1 2_19_08.pdf retrieved in 10/9/2011.

14. Fawole AO, Shah A, Fabanwo A, Predictors of maternal mortality in institutional deliveries in Nigeria. Afr Health Sci. 2012; 12(1):32-40.
15. Abou Zahr C. Maternal mortality overview. In Murray CJ \& Lopez AD (eds.). Health Dimensions of Sex and Reproduction. Global Burden of Disease and Injury Series. Geneva: World Health Organization. Harvard School of Public Health, World Bank, 2001.

16. Ujah IAO, Aisien OA, Mutihir JT: Factors contributing to maternal mortality in North Central Nigeria: A seventeen-year review. Afr J Reprod Health. 2005; 9:27-40.

17. Abe E, Omo-Aghoja LO. Maternal mortality at the Central Hospital, Benin Nigeria: A ten year review. Afr J Reprod Health. 2008; 12:17-26.

18. Harrison KA. Maternal mortality in Nigeria. Paper commissioned by the United Nations Fund for Population Activities (UNFPA) for the International Conference of the Society of Gynaecology and Obstetrics of Nigeria at Abuja, September 13, 1990.

19. Tsu VD. Appropriate technology to prevent maternal mortality: current research requirements. BJOG. 2005;112:1213-1. 